\title{
An overview of bone augmentation techniques
}

\author{
Reham AL Jasser ${ }^{1}$ and Sebastiano Andreana ${ }^{2}$ \\ ${ }^{1}$ Periodontist, Implant Fellow, Department of Restorative Dentistry, State University of New York at Buffalo, USA \\ ${ }^{2}$ Associate Professor, Director of Implant Dentistry, Department of Restorative Dentistry, State University of New York at Buffalo, USA
}

\begin{abstract}
The purpose of this review is to present several techniques available for augmenting and regenerating the deficient alveolar bone mainly for implant placement and restoring the lost bone for functional and esthetic purposes. These include, but are not limited to, the use of barrier membranes for guided bone regeneration, particulate grafting materials, block grafting techniques, distraction osteogenesis, ridge split techniques, the current applications of growth factors to accelerate the rate of bone formation, and enhance the quality of bone formed especially in severe defects, and finally, to discuss the combination staged approach of these techniques.
\end{abstract}

\section{Particulate bone grafting technique}

Particulate bone grafting is performed to repair a deficiency in contour and/or volume in dental arches. There is a wide variety of suggestions upon experts in the field regarding what particulate materials should be used for typical clinical applications, the rationale for their use, as well as combing one or more materials together, and the percentages of each material used in combination [1,2]. Bone grafts fall into main four categories, which are; autografts, allografts, xenografts, and alloplasts. The use of these materials in regenerative procedures is based on the assumption that they possess osteogenic potential by triggering the activation of bone-forming cells in the area to form new vital bone, or osteoinductive by containing bone inducing substances, or simply are osteoconductive by serving as a scaffold for bone formation, or having a combination action of all the previous [3]. It has been approved that autogenous bone harvested from intraoral or extraoral sites is the most predictable osteogenic organic graft for osseous tissue regeneration and hard tissue formation [4].

Main extraoral sites utilized in harvesting procedures include iliac crest which provides adequate quantity of graft material with excellent osteogenic, osteoinductive, and osteoconductive properties, however, high morbidity related to the second surgical site as well as root resorption were reported as side effects to this surgical procedure [5]. Therefore, in cases when availability of intraoral sites for harvesting graft material is limited, or donor site morbidities, or inadequate quantity of the harvested bone, the use of other grafting materials has been proposed whenever possible.

The autograft, allograft, alloplast, and xenograft materials all have reported success, alone or in combination with either growth factors, membranes or both. Autografts are considered to be the gold standard for most craniofacial and periodontal bone grafting for years, including the treatment of dental implant-related defects [6]. Several studies demonstrated the effectiveness of particulate autograft [7-9]. However, autografts have recognized several limitations including donor site morbidity, inadequate quantity and volume of graft material needed, potential resorption, and mismatch of particulate size desired [6,9].

Allografts are grafts transferred between members of the same species, which are genetically dissimilar. They have the advantage of being available in higher quantities and eliminate the morbidity associated with a second surgical site related to autografts. Allografts has been used as a substitute for autografts or in combination with autografts to enhance the quality of augmentation procedure [10]. Allograft are primarily used in the particulate form, although, other forms are available for usage such putty, gel, collagen sponge, sheets, as well as cortical or cancellous blocks also are used. Several studies regarding allografts showed that growth and differentiation factors are present in demineralized freezed dried bone allograft (DFDBA) preparations [11]. However, some reports revealed unpredictable or poor bone formation with some commercially available DFDBA [12]. The use of particulate allograft bone replacement substitute has been reported for numerous applications, including sinus augmentation [13], ridge augmentation [14], and in extraction socket preservation procedures [1]. In a comparative study between the use of mineralized freezed dried bone allograft (FDBA) and DFDBA for localized ridge and sinus augmentation, histologic observations showed regeneration of $42 \%$ new bone area with no statistical difference between the two materials. In regards to the risk for disease transmission among allografts, several studies have been conducted to examine the effectiveness of these materials' infection control processing and reported that disease transmission is approximately non-existent. However, concerns still exist for some patients and estimates for the risk were reported $[15,16]$ as the probability that DFDBA might contain HIV has been calculated to be one in 2.8 billion [17]. This has, in part, encouraged the attempts to identify alternative bone graft substitutes, such as those made from synthetic materials to overcome these patients' concerns.

Evolution in the field of dental biomaterials related to hard tissue

Correspondence to: Dr. Reham AL Jasser, BDS, MS, Diplomate of American Board of Periodontology, Tel: (716) 429-6644, E-mail: r.aljasser@gmail.com

Key words: dental implants, guided bone regeneration, bone grafting, surgical periodontal therapy

Received: March 02, 2016; Accepted: March 23, 2016; Published: March 26, 2016 
regeneration and engineering and further observation of limitations associated with the use of autografts and allografts have directed attention toward the invention and investigation of alloplastic graft materials [18]. These synthetic bone graft materials are osteoconductive with no osteogenesis or induction properties. Osteoconduction provides the ingrowth of capillaries, perivascular tissues, and osteoprogenitor cells from the adjacent recipient bed toward the area targeted for bone formation [19]. Main advantages of Alloplasts includes the absence of any restriction to the available quantity of graft, and the risk for disease transmission and need for harvesting bone tissue are eliminated. Further investigation have proved their success in dental surgical approaches such as alveolar ridge preservation, augmentation [20], and sinus grafting procedures [21,22]. As time passed by, these synthetic graft materials have been a well established alternative for autograft and allograft in surgical therapy for [23] two of the most used Alloplasts are Calcium sulfate (CS) and calcium phosphate (CP) compounds due to their biocompatibility, handling characteristics, porosity, different rates of dissolution, chemical and physical resemblance to bone mineral, and potentially unlimited supply at a modest cost [24-27]. Granular porous Hydroxy Apetite (HA) has been also considered a unique alloplast which is formed by the hydrothermal chemical conversion of sea coral from biogenic carbonate to HA [28]. Ridge augmentation with HA particulate, with and without autografts or plaster, was reported with success [29]. Sinus augmentation with HA showed also success and excellence in terms of dimensional stability when material was placed in the sinus. The second generation of CP bone cements has shown promise in hard tissue reconstruction in both craniofacial and orthopedic surgical fields, which also encouraged its use in implant related hard tissue reconstruction in the periodontal and maxillofacial fields [30].

Xenografts are derived from another species and are introduced to hard tissue reconstruction procedures since 1889 [31]. They showed to be biocompatible and osteoconductive. Xenografts are derived from a variety of animal sources, including bovine, porcine, equine, and coralline. They are found generally to be biocompatible and structurally similar to human bone. Many of these xenograft materials have the potential to resorb and be replaced with host bone over time $[32,33]$.

\section{Block grafting approaches}

Clinical studies stated that a considerable amount of horizontal augmentation can be added predictably to the defected bony area by the use of autogenous block graft in augmentation procedure [34,36]. In terms of failure rate, a study composed of 115 autogenous block grafts reported only one complete failure where the block was removed [36]. However, it is important to note that this surgical technique is highly technical sensitive. The stabilization and intimate contact of these blocks to well prepared recipient bed must be established with care to gain successful outcomes with this procedure $[37,38]$. Blocks' stabilization can be achieved with the use of bone fixation screws, which should not be less than two to prevent rotational movement of the block [39] or the simultaneous multiple implant placement simultaneously [40,41]. In addition, it is beneficial to keep the harvested block vascularized during the healing period, to increase the blood supply as well as the flow of esteoprogenitor cells to the area. This can be achieved by performing decortication during recipient bed preparation by intra-marrow penetration. It also has been shown that harvested block re-shaping and obtaining round edges can improve intimate contact of block and the remodeling process [42-44]. The healing of autogenous block grafts has been observed through having a formed viable bone to replace the necrotic bone within the block. This phenomena is called "creeping substitution". Autologous block graft techniques have been used frequently in different areas intra-orally in both maxilla and mandible where severe horizontal and vertical resorption of edentulous ridge is present. It showed a high success rate through time in both the maxilla and mandible. In contrast several complications can still be present with this procedure such as graft resorption, soft tissue dehiscence, and paresthesia which can make the decision of implant placement in the grafted area a challenge $[45,46]$.

The primary locations for harvesting intraoral block grafts include the external oblique ridge of the posterior mandible, ramus to obtain a block containing purely cortical bone, and symphysis to obtain a block which contains both cortical and cancellous bone. The revascularization of cortico-cancellous block grafts takes place in a much faster rate when compared to cortical bone block autografts. However, it's resorption rate tends to be much slower than particulate autografts. Revascularization of block grafts enables maintenance of their vitality, and, hence, reduces chances of graft infection and necrosis [37]. Intra oral block grafts harvest is found to be a preferable approach compared to the well-known extra-oral autogenous bone which is usually harvested from the iliac crest, cranium, or tibia due to ease of intraoral harvest and because of the fact that intra-oral bones are derived from intramembranous bone which have less resorption than endochondral bone that is the precursor of extra-oral bones [47].

In terms of post-operative resorption rates of autogenous block grafts, it is found to be in a range of $0 \%$ to $25 \%$ at the time of implant placement and up to $60 \%$ at the time of abutment connection placement. This associated resorption rate can be reduced by the used of a barrier membrane to cover the block at the time of the surgery $[48,49]$. A human study showed a percentage of $17 \%$ of resorption related to mandibular block grafts used in combination with particulate autograft and xenograft for vertical ridge augmentation, with an average gain of 5 $\mathrm{mm}$ and revealed a retained vitality of bock autografts used in this study [50]. Although autogenous bone grafts (as block or particulate form) remain the gold standard for ridge augmentation, donor site morbidity associated with block graft harvest has turned attention to the use of allogenic block graft materials. Case reports demonstrated success with FDBA and DFDBA block grafts for application in horizontal and vertical ridge augmentation procedures. However, further comparative studies with long periods of follow up are needed to evaluate the healing of these allogenic blocks from clincial and histological points of view [49].

\section{Combination approaches}

With reference to the aforementioned GBR techniques, combining on or more of the previously described approaches can be utilized in cases where severe bone defects are present in order to optimize GBR outcomes. In many situations, a membrane may not be required, and the graft material alone can be effective. However, it is found that the use of barrier membranes to cover the grafting material can further improve the quality of regeneration by holding grafting material in proper location which particulate grafts are used, acting as space maintenance and minimizing alveolar bone resorption. Barrier membranes can be non-resorbable, such as expanded polytetrafluoroethylene (ePTFE) and titanium, or resorbable, such as polypeptides (collagen) and synthetic polymers (polylactide and polyglycolide). These membranes may be used in combination with block grafts and/or particulate graft materials [50,51]. Membranes required for grafting of severe bony defect has to have a space maintenance property, which make them rigid enough to be shaped to the desired contour, height and width of future bone 
needed. This can be achieved by using commercially available nonresorbable titanium based and titanium reinforced membranes or the adjunct use of tenting screws and simultaneous placement of implants to prevent barrier membranes collapse into the space of the bony defects by the overlying soft tissue during healing [51]. In some reports where autografts were utilized for GBR purposes, resorption tended to be higher with when no membrane was used $[38,52]$. A clinical study reported a significantly less resorption of the block grafts was found when e-PTFE membranes were used to protect the graft. A histologic study that used autograft and barrier membranes in humans revealed a bone-implant contact of $22 \%$ in the $4 \mathrm{~mm}$ of vertically regenerated bone, compared to the $44 \%$ found in native bone. A 5 -year analysis of the vertical augmentation with this approach demonstrated stable vertical gains [53]. Finally, combination approaches may be considered when the grafting procedure is performed at the time of implant surgery to optimize gaining enough bone surrounding the implant, reduce the healing period and decrease the number of surgeries required as well as the morbidity and cost to the patient [54].

\section{Ridge expansion/ ridge splitting techniques}

Ridge splitting is an alternative to the various techniques described for horizontal ridge augmentation, such as distraction osteogenesis. It was proven that both pervious mentioned procedures have a similar healing pattern and end results. In an area with a narrow ridge measuring $3 \mathrm{~mm}$ in bucco-lingual width or more, splitting of the alveolar is started by using either chisels, osteotomes, or piezosurgical devices to increase the horizontal ridge width. Buccal and lingual cortical plates or targeted sites should not be fused and some intervening cancellous bone between those cortical plates should be present to prevent a complete bone fracture and separation. This technique has showed to be successful and comparable to alternative techniques in increasing horizontal ridge width providing that adequate vascularity and stabilization of the mobile bone segment is achieved along with sufficient inter-positional bone grafting and soft tissue protection. A long term clinical study evaluating more than 400 implants placed in expanded maxillary ridges by the previous mentioned technique showed that success rate of ridge split technique reached $97 \%$, which is consistent with placement in native bone in similar defects. As a modification of the ridge expansion of splitting technique, a two-phase approach to the ridge split technique was introduced to minimize the risk for unfavorable fractures of the segment in less flexible bone, and to maintain the segment vascularity during its expansion [12]. In the first surgery, a full-thickness mucoperiosteal flap is elevated on the buccal aspect of the ridge. A chesil, bur, or piezosurgical device is used to perform the apical horizontal, proximal, and distal vertical corticotomies. The crestal corticotomy can be made at the primary or secondary operation. A month later, the second surgery is performed by splitting and expansion of the ridge using osteotomes. At this stage, split-thickness buccal mucoperiosteal flap is elevated to preserve the vascularity of the buccal cortical plate. Implants can be placed in the space created between the buccal and lingual plates, with or without inter-positional grafting. The primary advantages of the ridge split technique using particulate, or GBR, compared to the mentioned lateral augmentation techniques, are to reduced treatment time and morbidity resulting from avoiding a separate donor site as well to avoid extra cost accompanied with the use of other grafting materials [37].

\section{Distraction osteogenesis}

Distraction osteogenesis is a procedure that is based on the longstanding biologic phenomenon that new bone fills a gap that is created between two separated pieces of bone. This separation should be done in slow rate and under tension. Distraction of the segment can be achieved in a vertical and/or a horizontal direction. The basic principles involved in distraction osteogenesis include a latency period of 7 days for initial post-surgical soft tissue regeneration and wound healing. A distraction phase during which the two pieces of bone undergo gradual incremental separation at a rate of $1 \mathrm{~mm}$ per day, and a consolidation phase that allows bone regeneration in the created space. Several studies showed a reliable success rate especially in gaining lost alveolar bone height with the use of variety of alveolar bone distractors $[55,56]$. Distractor devices can be either intraosseous or extraosseous. When the clinical requirement for significant vertical ridge augmentation exists, distraction osteogenesis can be used successfully with a variety of devices. Thorough assessment and treatment planning is crucial to achieve success with this procedure. For optimal bone augmentation of defects using distraction osteogenesis, are a minimum of 6 to $7 \mathrm{~mm}$ of bone height must be present above vital structures, such as inferior alveolar nerve in the mandible or maxillary sinus in the maxilla. The defect size is an another important factor when treatment is proposed using distraction osteogeneis, the vertical ridge defect size should not be less than of 3 to $4 \mathrm{~mm}$ and should be a span of three or more missing teeth [57]. The height of bone on adjacent teeth acts as reference points for the extent of vertical gain that can be achieved. Improvement of attachment levels on teeth with distraction has not been successful in animal models. Therefore, compromised dentition with considerable bone loss may need to be extracted to create a true vertical component of $4 \mathrm{~mm}$ within the defect span. Smaller ridge defects of a span of one or two missing teeth in width were associated with higher rates of complications when treated with the distraction technique $[58,59]$. In such cases, conventional ridge augmentation techniques should be considered to prevent associated complications. In terms of vertical gain using this approach, up to $9 \mathrm{~mm}$ of vertical bone gain was reported using implant like distractor in human case reports. Another device, with a small-diameter intraosseous approach, was used successfully with reporting the same amount of vertical gain. In contrast to these intraosseos distractos, an extraosseous distraction system with all moving components external to the cortical plate was developed and used successfully. The use of a prosthetic restorable distractor also was described showing a range of 4 to $6 \mathrm{~mm}$ of vertical height gain. Data on implant success in distracted bone out 3 to 5 years showed favorable results comparable to other grafting approaches which lead periodontists and surgeons to consider this approach as a valid option in regeneration proceders [60-62].

\section{Bone augmentation approaches using growth factors}

Incorporation of growth factors during regenerative therapy provides the opportunity to accelerate new bone formation and enhance soft tissue healing. Growth factors are the signaling molecules that modulate cell growth and development. They play a role in cell proliferation, migration, and extracellular matrix formation. Some of the most important growth factors involved in bone homeostasis include platelet-derived growth factor (PDGF), transforming growth factor- $\beta$, fibroblast growth factor, insulin-like growth factor, vascular endothelial growth factor, parathyroid hormone, and bone morphogenetic proteins (BMPs) [63]. The molecular approach using BMPs has received the most attention over the past decade. BMPs are differentiation factors that are part of the transforming growth factor super family. They have multiple effects, including the ability to differentiate osteoprogenitor cells into mineral-forming osteoblasts. Two of these proteins, BMP-2 and -7 (or osteogenic protein-1), have 
been investigated, studied extensively, and show promise for intraoral applications. Multiple human studies have been conducted to study the safety of BMPS and concluded that BMP-2 can be safely used intra-orally in surgical procedures such as ridge preservation and sinus augmentation $[64,65]$. Although BMP-2 has been approved by the Fodd and Drug Administration in the unites states of America (FDA) for human intraoral applications, the carriers and dosage of BMP-2 and -7 are still under regular review and investigation [66]. Another growth factor that receive the most attention in intra-oral application is PDGF. This growth factor has shown to be an important controller of osteogenesis in repair and regeneration circumstances. In an animal model, an attempt was done to test the effect of PDGF in forming new bone by the application of PDGF along with ePTFE membranes around immediate implants, this study revealed that PDGF lead to more rapid bone formation compared to the negative control. In another animal study evaluating recombinant human PDGF-BB (rhPDGF-BB) and inorganic bone blocks for vertical bone augmentation application, test sites with rhPDGF-BB showed statistically significantly more vertical bone growth than controls [67]. In terms of commercial availability, tri-calcium phosphate is used as a carrier for rh-PDGF with a concentration of $0.3 \mathrm{mg} / \mathrm{ml}$. This concentration was approved to be useful when used for bone regeneration. As with the differentiation factors, the optimal carriers and growth factor dosages are still under investigation and regulatory review for intraoral bone augmentation use. However, the field of growth and differentiation factors is still in a dynamic change and are regularly under investigation; therefore, to optimize the clinical outcome with different concentrations, types of carriers and release evaluations, further long term human clinical studies need to be performed [68].

Another growth factor approach is to use the patient's autogenous blood, extraction of the platelet-rich plasma (PRP) as well as plateletrich fibrin (PRF) after a specific preparation protocol and adding this concentrated group of autogenous growth factors to the grafting material by mixing or placing it on top of the grafting material. The addition of PRP to autogenous grafts showed a more rapid and dense bone formation compared to autogenous grafts used alone for bone augmentation. An improvement in bone formation when PRP is added to other graft materials has not been demonstrated clearly [69]. On the other hand, PRF has been proved to accelerate soft tissue healing however, its effect on bone regeneration is still in the process of investigation [70].

\section{Future approaches can be used for augmentaion}

Gene therapy is a relatively new therapeutic modality based on the potential for delivery of altered genetic material to the cell. The main aim of localized gene therapy is to increase the concentration of desired growth or differentiation factors in order to enhance the regenerative response and by that improving the regeneration process in the targeted area [70]. The gene therapy is initially introduced as the process of facilitating the body to deliver high doses of autogenous BMP to promote bone regeneration. This current method of delivering higher concentrations of growth factors to local bone augmentation site over longer periods of time shows promise but still need further investigation to obtain acceptable clinical results and most importantly, to assure its safety. A cellular tissue engineering strategy that exploits the regenerative capacity of bone may include the in vitro amplification of osteoblast cells or osteoprogenitor cells grown within threedimensional constructs [71]. Approaches specifically targeting intraoral bone augmentation demonstrated in vitro osteoblast amplification in different constructs. Alternatively, the use of mesenchymal stem cells for construct seeding or development of an immortalized osteoblast line showed promise for bone regeneration. These amplification approaches, in combination with gene therapy and molecular stimulation, may lead to improved approaches for multifactorial tissue engineering strategies aimed at alveolar bone augmentation. Other tissue engineering approaches include cell culture to create cell sheets from fibroblasts, or scaffolds rich in cells that can form membranes, as well as the use of stem cells and immortalized dental follicle cells is still being studied to be used for bone formation and regeneration purposes [72].

\section{Conclusions}

Several techniques have been found to aid in approaching a successful bone augmentation to facilitate reaching a proper bone dimensions and correct placement of dental implants. Suitable technique must be selected after careful evaluation of defected area and consider related factors such as the extent of the defect, patient preference, surgeon expertise, available materials and instruments, cost, and ease of specific procedures to be performed. It is important to review all applied successful techniques and available materials to enhance proper selection of method to reach best outcomes and high success rates. It is advisable to use an evidenced-based approach when a treatment plan is being developed for bone augmentation cases to predict final outcomes and to set accurate expectations of the final results of the augmentation procedure. This can enhance the quality of final implant being placed and facilitate improve patient's satisfaction.

\section{References}

1. Furusawa T, Mizunuma K (1997) Osteoconductive properties and efficacy of resorbable bioactive glass as a bone-grafting material. Implant Dent 6: 93-101. [Crossref]

2. Berglundh T, Lindhe J (1997) Healing around implants placed in bone defects treated with Bio-Oss. An experimental study in the dog. Clin Oral Implants Res 8: 117-124. [Crossref]

3. McAllister BS, Haghighat K (2007) Bone augmentation techniques. J Periodontol 78 377-396. [Crossref]

4. Evian CI, Rosenberg ES, Coslet JG, Corn H (1982) Theosteogenic activity of bone removed from healing extraction sockets in humans. J Periodontol 53: 81-85. [Crossref]

5. Schallhorn RG, Hiatt WH, Boyce W (1970) Iliac transplants in periodontal therapy. $J$ Periodontol 41: 566-580. [Crossref]

6. Mellonig JT (1992) Autogenous and allogeneic bone grafts in periodontal therapy. Crit Rev Oral Biol Med 3: 333-352. [Crossref]

7. Mulliken JB, Glowacki J (1980) Induced osteogenesis for repair and construction in the craniofacial region.PlastReconstrSurg65: 553-560. [Crossref]

8. Macewen W (1909) I. Intrahuman Bone Grafting and Reimplantation of Bone. Ann Surg 50: 959-968. [Crossref]

9. Hiatt WH, Schallhorn RG (1973) Intraoral transplants of cancellous bone and marrow in periodontal lesions.J Periodontol 44: 194-208. [Crossref]

10. Mellonig JT (1992) Autogenous and allogeneic bone grafts in periodontal therapy. Crit Rev Oral Biol Med 3: 333-352. [Crossref]

11. Mellonig JT (1984) Decalcified freeze-dried bone allograft as an implant material in human periodontal defects. Int J Periodontics Restorative Dent 4: 40-55. [Crossref]

12. Becker W, Urist MR, Tucker LM, Becker BE, Ochsenbein C (1995) Human demineralized freeze-dried bone: inadequate induced bone formation in athymic mice. A preliminary report. J Periodontol 66: 822-828. [Crossref]

13. Whittaker JM, James RA, Lozada J, Cordova C, GaRey DJ (1989) Histological response and clinical evaluation of heterograft and allograft materials in the elevation of the maxillary sinus for the preparation of endosteal dental implant sites. Simultaneous sinus elevation and root form implantation: An eight-month autopsy report. J Oral Implantol 15:141-144. [Crossref]

14. Cochran DL, Douglas HB (1993) Augmentation of osseous tissue around 
nonsubmergedendosseous dental implants. Int $J$ Periodontics Restorative Dent 13: 506-519. [Crossref]

15. Buck BE, Resnick L, Shah SM, Malinin TI (1990) Human immunodeficiency virus cultured from bone. Implications for transplantation.ClinOrthopRelat Res 249-253. [Crossref]

16. Mellonig JT, Prewett AB, Moyer MP (1992) HIV inactivation in a bone allograft. $J$ Periodontol 63: 979-983. [Crossref]

17. Russo R, Scarborough N (1995) Inactivation of viruses in demineralized bone matrix. FDA workshop on tissue transplantation and reproductive tissue, June 20-21, 1995. N Engl J Med 326:726-732.

18. Hench LL (1998) Bioactive materials: the potential for tissue regeneration. $J$ Biomed Mater Res 41: 511-518. [Crossref]

19. Burchardt H (1983) The biology of bone graft repair. Clin Orthop Relat Res 28-42. [Crossref]

20. Pinholt EM, Bang G, Haanaes HR (1990) Alveolar ridge augmentation by osteoinduction in rats. Scand J Dent Res 98: 434-441. [Crossref]

21. Furusawa T, Mizunuma K (1997) Osteoconductive properties and efficacy of resorbable bioactive glass as a bone-grafting material. Implant Dent 6: 93-101. [Crossref]

22. Tadjoedin ES1, de Lange GL, Holzmann PJ, Kulper L, Burger EH (2000) Histologica observations on biopsies harvested following sinus floor elevation using a bioactive glass material of narrow size range. Clin Oral Implants Res 11:334-344. [Crossref]

23. Hamilton D (1881)On sponge grafting. J AnatPhysiol27:385-414.

24. Han T, Carranza FA Jr, Kenney EB (1984) Calcium phosphate ceramics in dentistry: a review of the literature.J West Soc Periodontol Periodontal Abstr 32: 88-108. [Crossref]

25. Jarcho M (1986) Biomaterial aspects of calcium phosphates. Properties and applications.Dent Clin North Am 30: 25-47. [Crossref]

26. Perry CR (1999) Bone repair techniques, bone graft, and bone graft substitutes.Clin Orthop Relat Res 71-86. [Crossref]

27. Kutkut A, Andreana S, Kim HL, Monaco E Jr (2012) Extraction socket preservation graft before implant placement with calcium sulfate hemihydrate and platelet-rich plasma: a clinical and histomorphometric study in humans. J Periodontol83:401-9. [Crossref]

28. Roy DM, Linnehan SK (1974) Hydroxyapatite formed from coral skeletal carbonate by hydrothermal exchange.Nature 247: 220-222. [Crossref]

29. White E, Shors EC (1986) Biomaterial aspects of Interpore-200 porous hydroxyapatite Dent Clin North Am 30: 49-67. [Crossref]

30. Frame JW, Rout PG, Browne RM (1987) Ridge augmentation using solid and porous hydroxylapatite particles with and without autogenous bone or plaster.J Oral MaxillofacSurg45:771-778. [Crossref]

31. [No authors listed] (1889) Senn on the Healing of Aseptic Bone Cavities by Implantation of Antiseptic Decalcified Bone.Ann Surg 10: 352-368. [Crossref]

32. Wallace SS, Froum SJ, Tarnow DP (1996) Histologic evaluation of a sinus elevation procedure: A clinical report. Int J Periodontics Restorative Dent 16: 46-51. [Crossref]

33. Thaller SR, Hoyt J, Borjeson K, Dart A, Tesluk H (1993) Reconstruction of calvarial defects with anorganic bovine bone mineral (Bio-Oss) in a rabbit model. $J$ CraniofacSurg4: 79-84. [Crossref]

34. Misch CM (1997) Comparison of intraoral donor sites for onlay grafting prior to implant placement. Int J Oral Maxillofac Implants 12: 767-776. [Crossref]

35. Pikos MA (1999) Block autografts for localized ridge augmentation: Part I. The posterior maxilla. Implant Dent 8: 279-285. [Crossref]

36. Pikos MA (2000) Block autografts for localized ridge augmentation: Part II. The posterior mandible. Implant Dent 9: 67-75. [Crossref]

37. deCarvalho PS, Vasconcellos LW, Pi J (2000) Influence of bed preparation on the incorporation of autogenous bone grafts: a study in dogs. Int J Oral Maxillofac Implants 15: 565-570. [Crossref]

38. Lin KY, Bartlett SP, Yaremchuk MJ, Fallon M, Grossman RF, et al. (1990) The effect of rigid fixation on the survival of onlay bone grafts: an experimental study. Plast Reconstr Surg 86: 449-456. [Crossref]

39. Urbani G, Lombardo G, Santi E, Tarnow D (1998) Localized ridge augmentation with chin grafts and resorbable pins: case reports. Int J Periodontics Restorative Dent 18 : 363-375. [Crossref]
40. Isaksson S, Alberius P (1992) Maxillary alveolar ridge augmentation with onlay bonegrafts and immediate endosseous implants. J Craniomaxillofac Surg 20: 2-7. [Crossref]

41. Jensen J, Sindet-Pedersen S (1991)Autogenous mandibular bone grafts and osseointegrated implants for reconstruction of the severely atrophied maxilla: A preliminary report. J Oral Maxillofac Surg 49:1277-1287. [Crossref]

42. Majzoub Z, Berengo M, Giardino R, Aldini NN, Cordioli G (1999) Role of intramarrow penetration in osseous repair: a pilot study in the rabbit calvaria. $J$ Periodontol 70 : 1501-1510. [Crossref]

43. Albrektsson T (1980) In vivo studies of bone grafts. The possibility of vascular anastomoses in healing bone. Acta Orthop Scand 51: 9-17. [Crossref]

44. Albrektsson T (1980) Repair of bone grafts. A vital microscopic and histological investigation in the rabbit.Scand J Plast Reconstr Surg 14: 1-12. [Crossref]

45. Burchardt H, Enneking WF (1978) Transplantation of bone. Surg Clin North Am 58 403-427. [Crossref]

46. Schwartz-Arad D, Levin L, Sigal L (2005) Surgical success of intraoral autogenous block onlay bone grafting for alveolar ridge augmentation. Implant Dent 14: 131-138. [Crossref]

47. Zins JE, Whitaker LA (1983 Membranous versus endochondral bone: Implications for craniofacial reconstruction. Plast Reconstr Surg72: 778-785. [Crossref]

48. Misch CM1, Misch CE, Resnik RR, Ismail YH (1992) Reconstruction of maxillary alveolar defects with mandibular symphysis grafts for dental implants: A preliminary procedural report. Int J Oral Maxillofac Implants 7:360-366. [Crossref]

49. Raghoebar G, Batenburg RH, Vissink A, Reintsema H (1996) Augmentation of localized defects of the anterior maxillary ridge with autogenous bone before insertion of implants.J Oral Maxillofac Surg 54: 1180-1185. [Crossref]

50. Jardini MA, De Marco AC, Lima LA (2005) Early healing pattern of autogenous bone grafts with and without e-PTFE membranes: a histomorphometric study in rats.Oral Surg Oral Med Oral Pathol Oral Radiol Endod 100: 666-673. [Crossref]

51. Keith JD Jr (2004) Localized ridge augmentation with a block allograft followed by secondary implant placement: a case report. Int J Periodontics Restorative Dent 24 11-17. [Crossref]

52. Malmquist J (1995)Osteopromotion in osseointegration techniques: The use of membrane technique to regenerate bone with endosseous implants for maxillofacia reconstruction In: Block MS, Kent JN (Eds.), Endosseous Implants for Maxillofacial Reconstruction. Philadelphia: W.B. Saunders Company; 437.

53. Malmquist JP (1999) Successful implant restoration with the use of barrier membranes. J Oral Maxillofac Surg 57: 1114-1116. [Crossref]

54. ten Bruggenkate CM, Kraaijenhagen HA, van der Kwast WA, Krekeler G, Oosterbeek HS (1992) Autogenous maxillary bone grafts in conjunction with placement of I.T.I. endosseous implants. A preliminary report. Int J Oral Maxillofac Surg 21: 81-84. [Crossref]

55. Jovanovic SA, Nevins M (1995) Bone formation utilizing titanium-reinforced barrier membranes. Int J Periodontics Restorative Dent 15: 56-69. [Crossref]

56. Adell R, Lekholm U, Grondahl K, et al. Reconstruc- tion of severely resorbed edentulous maxillae using osseointegrated fixtures in immediate autogenous bone grafts. Int J Oral Maxillofac Implants 5: 233-246. [Crossref]

57. Ilizarov GA (1971) [Basic principles of transosseous compressionand distraction osteosynthesis]. Ortop Travmatol Protez 32: 7-15. [Crossref]

58. Ilizarov GA (1989) The tension-stress effect on the genesis and growth of tissues: Part II. The influence of the rate and frequency of distraction.Clin Orthop Relat Res 263 285. [Crossref]

59. Chiapasco M, Romeo E, Vogel G (2001) Vertical distraction osteogenesis of edentulous ridges for improvement of oral implant positioning: a clinical report of preliminary results.Int J Oral Maxillofac Implants 16: 43-51. [Crossref]

60. McAllister BS, Gaffaney TE (2003) Distraction osteogenesis for vertical bone augmentation prior to oral implant reconstruction.Periodontol 2000 33: 54-66. [Crossref]

61. Bavitz JB, Payne JB, Dunning D, Glenn A, Koka R (2000) The use of distraction osteogenesis to induce new suprabony periodontal attachment in the beagle dog.Int J Periodontics Restorative Dent 20: 596-603. [Crossref]

62. Jensen OT, Cockrell R, Kuhike L, Reed C (2002) Anterior maxillary alveolar distraction osteogenesis: a prospective 5-year clinical study. Int J Oral Maxillofac Implants 17: 52 68. [Crossref] 
63. Proussaefs P, Lozada J (2003)The use of resorbablecolla- gen membrane in conjunction with autogenous bone graft and inorganic bovine mineral for buccal/labial alveolar ridge augmentation: A pilot study. J Prosthet Dent 90 : 530-538.[Crossref]

64. Chiapasco M, Consolo U, Bianchi A, Ronchi P (2004) Alveolar distraction osteogenesis for the correction of vertically deficient edentulous ridges: a multicenter prospective study on humans. Int J Oral Maxillofac Implants 19: 399-407. [Crossref]

65. Taba M Jr, Jin Q, Sugai JV, Giannobile WV (2005) Current concepts in periodontal bioengineering. Orthod Craniofac Res 8: 292-302. [Crossref]

66. Howell TH, Fiorellini J, Jones A, Alder M, Nummikoski P, et al. (1997) A feasibility study evaluating rhBMP-2/absorbable collagen sponge device for local alveolar ridge preservation or augmentation. Int J Periodontics Restorative Dent 17: 124-139. [Crossref]

67. Margolin MD, Cogan AG, Taylor M, Buck D, McAllister TN, et al. (1998) Maxillary sinus augmentation in the non-human primate: A comparative radiographic and histologic study between recombinant human osteogenic protein-1 and natural bone mineral. J Periodontol 69: 911-919. [Crossref]

68. Boyne PJ, Nath R, Nakamura A (1998) Human recombinant BMP-2 in osseous reconstruction of simulated cleft palate defects. Br J Oral Maxillofac Surg 36: 84-90. [Crossref]

69. Becker W, Lynch SE, Lekholm U, Becker BE, Caffesse R, et al. (1992)A comparison of ePTFE membranes alone or in combination with platelet-derived growth factors and insulin-like growth factor-I or demineralized freeze-dried bone in promoting bone formation around immediate extraction socket implants. J Periodontol63: 929-940. [Crossref]

70. Nevins M, Giannobile WV, McGuire MK, Kao RT, Mellonig JT,et al. Platelet-derived growth factor stimulates bone fill and rate of attachment level gain: Results of a large multicenter randomized controlled trial. J Periodontol 2005; 76:2205-2215. [Crossref]

71. Marx RE, Carlson ER, Eichstaedt RM, Schimmele SR, Strauss JE, et al. (1998) Platelet-rich plasma: Growth factor enhancement for bone grafts.Oral Surg Oral Med Oral Pathol Oral Radiol Endod 85: 638-646. [Crossref]

72. Jang ES, Park JW, Kweon H, Lee KG, Kang SW, et al. (2010) Restoration of periimplant defects in immediate implant installations by Choukroun platelet-rich fibrin and silk fibroin powder combination graft.Oral Surg Oral Med Oral Pathol Oral Radiol Endod 109: 831-836. [Crossref]

73. Lieberman JR, Daluiski A, Stevenson S, Wu L, McAllister P, et al. (1999) The effect of regional gene therapy with bone morphogenetic protein-2-producing bone-marrow cells on the repair of segmental femoral defects in rats.J Bone Joint Surg Am 81: 905917. [Crossref]

74. Breitbart AS, Grande DA, Mason JM, Barcia M, James T, et al. (1999) Gene- enhanced tissue engineering: Applications for bone healing using cultured periosteal cells transduced retrovirally with the BMP-7 gene. Ann Plast Surg 42:488-495. [Crossref]

75. Jin QM, Anusaksathien O, Webb SA, Rutherford RB, Giannobile WV (2003) Gene therapy of bone morphogenetic protein for periodontal tissue engineering. JPeriodontol 74: 202-213. [Crossref]

Copyright: C2016 AL Jasser R. This is an open-access article distributed under the terms of the Creative Commons Attribution License, which permits unrestricted use, distribution, and reproduction in any medium, provided the original author and source are credited. 